\title{
From Bench-scale Test Data to Predictors of Full- scale Fire Test Results
}

SOONIL NAM, JOHN DE RIS, PETER WU, and ROBERT BILL, JR.

FM Global

1151 Boston-Providence Turnpike

Norwood, Massachusetts, USA

\begin{abstract}
There is a strong desire in the fire safety community for methods that use bench-scale test data to predict the final outcome of full-scale fire tests. The current project has the objective of meeting this goal through modeling an intermediate-scale test called the parallel panel test and comparing the results of the test with FM Approvals $25 \mathrm{ft}$ Corner Test (ANSI FM 4880). The Corner Test has been used to evaluate the fire hazard of insulated wall and plastic interior/exterior building panels. As the first step of the project, a model predicting the total heat release rates from the burning parallel panel tests using the data obtained by the bench-scale tests was developed. The heat release rates of the sand burner at the bottom of the parallel panels were varied during the tests for each different panel material. The results of the comparison were very favorable. However, comparisons with the $25 \mathrm{ft}$ Corner Tests indicate that an improved correlation with the parallel panel configuration could be obtained by a modification of the space and the burner size.
\end{abstract}

KEYWORDS: bench-scale/full-scale fire test, flame spread, parallel panel test INTRODUCTION

Due to the costs and the time associated with conducting large-scale fire tests, there is a strong desire for bench-scale test data to be utilized to predict the final outcomes of fullscale tests. Although the main objective of the bench-scale tests is obtaining fundamental characteristics of test materials, there is no accepted methodology for extracting material property that have been shown to predict fire behaviors in many fire tests used for certification. This is true even for homogeneous materials, and the problems are compounded for inhomogeneous ones. It is, therefore, a constant challenge for engineers to establish an adequate way of conducting bench-scale tests and properly interpret the data to make a link to full-scale tests.

The fire hazard of insulated wall, wall and roof/ceiling panels, and plastic interior/exterior finish materials have been traditionally evaluated at FM Global through FM Approvals' $25 \mathrm{ft}$ Corner Tests [1]. In the tests, test samples are attached to steel frames as can be seen in Fig. 1. The east wall (long) frame is $15.7 \mathrm{~m}$ long, and the south wall frame is $11.96 \mathrm{~m}$ long. The distance between the concrete floor and the bottom of the ceiling furring strips is $7.54 \mathrm{~m}$. The test fire load is conditioned oak pallets, which is stacked maximum $1.5 \mathrm{~m}$ high at the intersection of the assembly walls, $0.3 \mathrm{~m}$ apart from each wall. The stack of pallets is ignited and the test continues for $15 \mathrm{~min}$. During the test period, the flames from the burning material should not reach any of the limits of the corner test structure in order to pass the test.

It would be very convenient if relatively simple and inexpensive bench-scale tests can be used in lieu of the full-scale test to assess the flammability of the materials. The current knowledge on the subject, however, is not sufficient enough for bench-scale tests to be 
directly used to make adequate predictions of the results of the full-scale $25 \mathrm{ft}$ Corner Tests except in the case of thermoset materials using thermal barrier [1]. Thus, it was proposed to devise an intermediate-scale test that can bridge the gap between the benchscale tests and the full-scale tests. Parallel panel tests (PPT), which will be described in detail shortly, were chosen as the intermediate-scale tests.

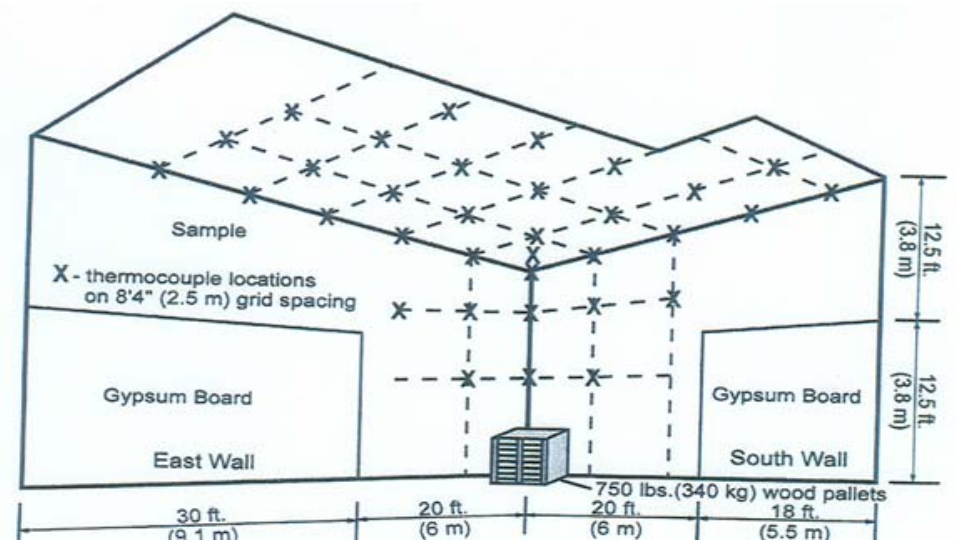

Fig. 1. The $25 \mathrm{ft}$ corner test structure.

The parallel panel tests have already been used for the screening of the FM Approvals' 4910 materials [2] that are used in clean rooms. Earlier work of Alpert [3] showed the feasibility of establishing a model of the PPT as the intermediate-scale tests that will lead the bench-scale test data to the prediction of the outcome of the $25 \mathrm{ft}$ Corner Tests. The model used here and discussed below is a revised version of that discussed by Alpert [3]. The methodology adopted in the earlier model [3] for extracting the inputs from benchscale testing was not consistently prescribed, and in consequence the resulting predictions of the PPT results based on those inputs were not reliable. Development of a more reliable methodology and the methodology tested against many new sets of test data will be the subjects of this paper. The comparison of the parallel panel results with that of the $25 \mathrm{ft}$ corner tests will be discussed too.

\section{INTRODUCTION TO PARALLEL PANEL TEST (PPT)}

The parallel panel test configuration that is being used as a screening tool of the FM 4910 clean-room materials was well described by Alpert [3]. It consists of two parallel panels, each $2.4 \mathrm{~m}$ high by $0.6 \mathrm{~m}$ wide, maintaining a $0.3 \mathrm{~m}$ clearance in between. The $2: 1$ aspect ratio of the panel width to the clearance was chosen to provide the same view factor as that of the Corner Test. A sand burner located at the bottom of the panels continuously provides heat during the tests.

Table 1 shows the materials and conditions associated with PPT. The test materials were chosen in such a way that they are close to the borderline materials on which fire may or may not propagate depending on test conditions. The first column shows the material identification numbers used in the tests. The material numbers 1089, 1090, 1095, and 1117 referred to PVC, the material numbers 1096 and 1097 referred to fire-retarded (FR) plywood, and the material number 1098 referred to ordinary plywood. The thickness of 1089 was $9.5 \mathrm{~mm}$; 1090, 1117, and 1096 was $12.6 \mathrm{~mm}$; and 1095, 1096, and 1098 was $19.1 \mathrm{~mm}$. The second column shows the heat release rate supplied to the panels by the 
sand burner at each test, which was called "exposure" and denoted as $\dot{Q}_{b}$. The third column shows the measured total heat release rate generated by the burning parallel panels plus that of the sand burner in each test. The last column describes the observation associated with fire propagation. The other columns not mentioned here will be described later.

Table 1. Parallel panel fire test estimations and results.

\begin{tabular}{|c|c|c|c|c|c|c|}
\hline $\begin{array}{c}\text { Material } \\
\#\end{array}$ & $\begin{array}{r}\text { Exposure } \\
\dot{Q}_{b}(\mathbf{k W})\end{array}$ & $\begin{array}{c}\text { Measured } \\
\dot{Q}_{c h}(\mathbf{k W})\end{array}$ & $\Gamma$ & $\mathbf{Y}_{\text {sp }}$ & $\begin{array}{c}\text { Estimated } \\
\dot{Q}_{c h}(\mathbf{k W})\end{array}$ & $\begin{array}{l}\text { Propagation } \\
\text { Observation }\end{array}$ \\
\hline 1089 & 28 & 40 & 2.43 & 0.173 & 68 & No in $10 \mathrm{~min}$ \\
\hline 1089 & 38 & 260 & 2.43 & 0.173 & 210 & No in $10 \mathrm{~min}$ \\
\hline 1089 & 59 & $>750$ & 2.43 & 0.173 & 540 & Yes in $6 \mathrm{~min}$ \\
\hline 1090 & 43 & 68 & 2.37 & 0.179 & 228 & No in $10 \mathrm{~min}$ \\
\hline 1090 & 48 & 76 & 2.37 & 0.179 & 288 & No in $10 \mathrm{~min}$ \\
\hline 1090 & 64 & 120 & 2.37 & 0.179 & 481 & No in $10 \mathrm{~min}$ \\
\hline 1095 & 70 & 100 & 1.94 & 0.095 & 129 & No in $20 \mathrm{~min}$ \\
\hline 1095 & 81 & 125 & 1.94 & 0.095 & 156 & No in $20 \mathrm{~min}$ \\
\hline 1095 & 92 & 160 & 1.94 & 0.095 & 183 & No in $14 \mathrm{~min}$ \\
\hline 1117 & 60 & $>210$ & 2.55 & 0.133 & 415 & Yes in $13 \mathrm{~min}$ \\
\hline 1117 & 80 & $>310$ & 2.55 & 0.133 & 658 & Yes in $11 \mathrm{~min}$ \\
\hline 1096 & 80 & 132 & 2.95 & 7.6E-3 & 156 & No in $20 \mathrm{~min}$ \\
\hline 1096 & 100 & 180 & 2.95 & $7.6 \mathrm{E}-3$ & 207 & No in $20 \mathrm{~min}$ \\
\hline 1097 & 92 & 280 & 2.2 & $9.9 \mathrm{E}-3$ & 148 & No in $20 \mathrm{~min}$ \\
\hline 1097 & 103 & 250 & 2.2 & $9.9 \mathrm{E}-3$ & 169 & No in $20 \mathrm{~min}$ \\
\hline 1098 & 92 & $>400$ & 3.41 & 0.065 & SFP & Yes in 3-4 min \\
\hline
\end{tabular}

\section{BENCH-SCALE TESTS}

The Fire Propagation Apparatus (FPA) specified in ASTM E 2058 [4] was used in the bench-scale tests. The test samples were $0.094 \mathrm{~m}$ diameter specimens. As shown in Fig. 2, the external heat fluxes were provided by radiative heat from the heaters surrounding the specimen. The bench-scale tests at FPA provided the following: 


\section{Estimation of $\Delta H_{c}$}

The heat of combustion, $\Delta H_{c}$, was estimated from the FPA data conducted with: (i) 50 $\mathrm{kW} / \mathrm{m}^{2}$ external heat flux under (ii) ordinary air flow. The heat of combustion is "the accumulated chemical heat release divided by the mass loss during the period of active flaming [at FPA]."

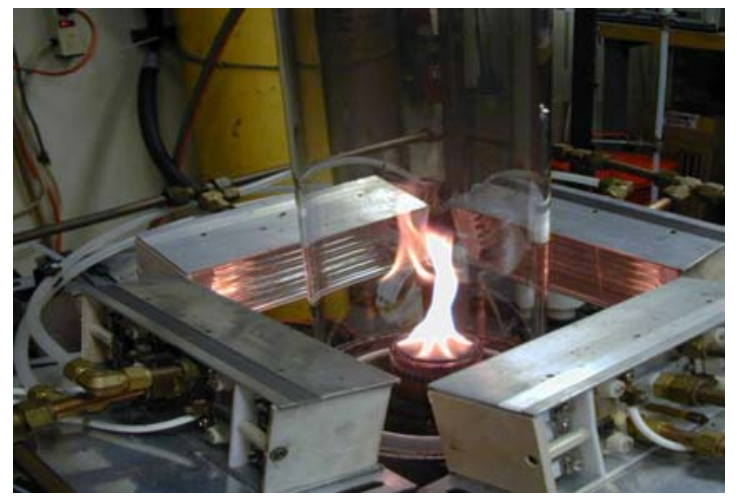

Fig. 2. Combustion section of the fire propagation apparatus (FPA).

\section{Estimation of $\mathbf{Y}_{\text {sp }}$}

The smoke yield, $\mathrm{Y}_{\mathrm{sp}}$, of a burning material was defined as the mass of the generated smoke per mass loss of the fuel. It was estimated from the FPA combustion data (see Item 3.1 above), particularly with the extinction coefficient obtained from the red wave length $(632.8 \mathrm{~nm})[4]$.

Estimation of $\Delta H_{g}$

The heat of gasification, $\Delta H_{g}$, was estimated from the data obtained through FPA with:

(i) various external heat fluxes under (ii) $100 \%$ nitrogen flow. When the FPA data, mass pyrolysis rate vs. time per external heat flux, were approximately steady throughout the experiment, the full ranges of the tests were used to calculate mass pyrolysis rates. However, when the data fluctuate significantly with time---thus, several peaks appeared in mass loss rates---then the mass loss rates calculated in the very first linear slope were used. The rationale was that the mass-loss rates in the first peak, among other rates, were the most significant in determining fire propagation tendency of test materials. This treatment is different from that in [3], where the analysis was based upon mass loss rate appeared to be steady from the numerically differentiated data, which led to inconsistent results. Once the average mass pyrolysis rates vs. external heat fluxes are obtained, linear curve fitting was performed to find out the "heat of gasification." The average mass pyrolysis rates per unit sample surface area were in the abscissa and the external heat fluxes were in the ordinate. The slope of the curve would be the heat of gasification and the point where the curve intersects the ordinate would be the critical heat flux, under which pyrolysis of the given material cannot be sustained. 


\section{Computation of $\dot{Q}_{c h}$}

Following Alpert [3], the chemical heat release rate or the total heat release rate of PPT, $\dot{Q}_{c h}$, was the sum of the heat release rate of the sand burner and the heat generated by the burning panels. It can be given as

$\dot{Q}_{c h}=\dot{Q}_{b}+2 \dot{Q}_{\text {panel }}$

where $\dot{Q}_{\text {panel }}$ can be given as

$\dot{Q}_{\text {panel }}=\frac{\dot{Q}_{s w}}{\Delta H_{g}} \Delta H_{c}=\Gamma \dot{Q}_{s w}$

Here $\dot{Q}_{S w}$ is the heat flux absorbed by one panel surface during the test, and $\Gamma$ refers to the ratio of the heat of combustion to the heat of gasification (i.e., $\Gamma \equiv \Delta H_{c} / \Delta H_{g}$ ). The $\frac{\dot{Q}_{S W}}{\Delta H_{g}}$ in the equation corresponds to the mass generation rate of fuel by the gasification of the panel material caused by the heat flux absorbed by the panel. Thus, the gasified material from a panel will burn with the heat generation rate of $\frac{\dot{Q}_{s w}}{\Delta H_{g}} \Delta H_{c}$. de Ris and Orloff [5] measured the flame heat flux at each panel surface for different fuels over a range of different total heat release rates. They also showed that the heat flux on the panel surface vs. the total heat release rates from various fuels can be correlated well when $\dot{Q}_{c h} / l_{s}^{0.25}$ was used in lieu of $\dot{Q}_{c h}$. Here $l_{s}$ is the "smoke point" [6] defined as the minimum height of a laminar flame in which the first soot particles exit the flame tip. As it is difficult to measure the smoke point for solid materials, a conversion of $l_{s}$ with $Y_{s}$, smoke yield rate, was sought with Tewarson's correlation [7]. The final functional form, which is shown in Fig 3, can be given as Eq. 3.

$\dot{Q}_{c h}=\dot{Q}_{b}+2 \Gamma\left(-4.1324+0.30335 \beta+\frac{20.2290}{\beta}-\frac{17.0876}{\beta^{1.5}}\right)$

where $\beta \equiv \dot{Q}_{c h} Y_{s}^{0.25}$. Here, $\mathrm{Y}_{\mathrm{s}}$ was estimated as

$Y_{s}=\frac{\dot{Q}_{b}}{\dot{Q}_{c h}} Y_{s b}+\frac{\left(\dot{Q}_{c h}-\dot{Q}_{b}\right)}{\dot{Q}_{c h}} Y_{s p}$ 


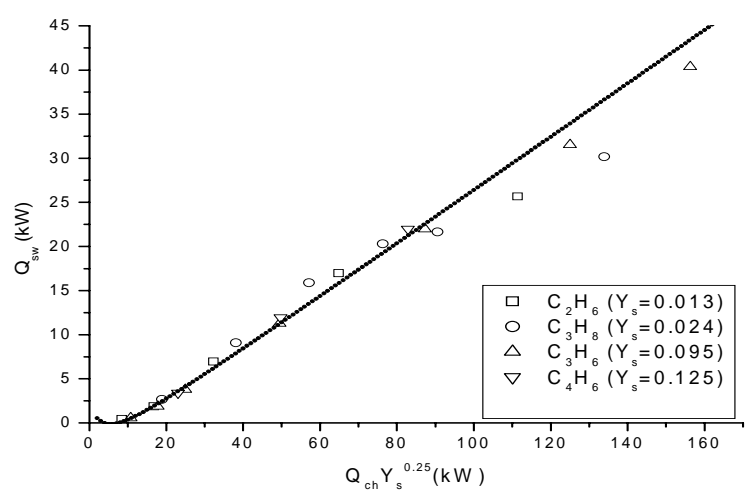

Fig. 3. Heat flux delivered to the panel surface.

where $\mathrm{Y}_{\mathrm{sb}}$ is the smoke yield of the sand burner fuel, i.e., pure propane, and the value of 0.024 is used, and $\mathrm{Y}_{\mathrm{sp}}$ is the smoke yield of the burning material that was measured at FPA. Now the total heat release rate at PPT at each test can be computed by solving Eq. 3 with an iterative scheme.

\section{COMPUTING THE TOTAL HEAT RELASE RATE AT EACH PARALLEL PANEL TEST USING THE BENCH-SCALE DATA}

The following examples will show how the estimation of the total heat release rates was obtained. Two materials in Table 1 that required different ways to estimate the heat of gasification (see 3.3) will be discussed.

\section{Item \#1089 (PVC)}

Estimation of $\Delta H_{c}$

The data from the FPA bench-scale test are given in Figs. 4 and 5. They are the accumulated mass loss $(m)$, accumulated smoke mass $(S)$, accumulated combustion energy $(E)$, and mass burning rate in combustion of \# 1089.

Figures 4 and 5 indicate that the active combustion period can be taken as $70 \mathrm{~s}<\mathrm{t}<700 \mathrm{~s}$. The heat of combustion can be estimated from the figures as

$\Delta H_{c}=\frac{E_{t=700}-E_{t=70}}{m_{t=700}-m_{t=70}}=\frac{461.54-0.72}{80.57-2.48}=5.90(\mathrm{~kJ} / \mathrm{g})$

Estimation of $Y_{s p}$.

The smoke yield can be estimated from Fig. 4 as

$Y_{s p}=\frac{S_{t=700}-S_{t=70}}{m_{t=700}-m_{t=70}}=\frac{13.7286-0.20709}{80.57-2.48}=0.173(\mathrm{~g} / \mathrm{g})$.

Overall, the properties associated with combustion tests are insensitive to where and how the periods for the estimation are chosen. 


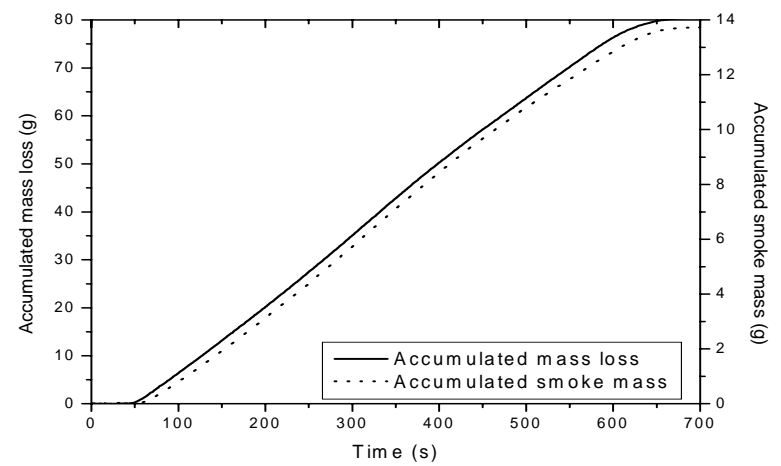

Fig. 4. Accumulated mass loss and accumulated smoke mass in combustion of \#1089.

Estimation of $\Delta H_{g}$

Figure 6 shows the accumulated pyrolysis mass loss per time $(m)$ vs. external heat fluxes $\left(\dot{q}_{e}^{\prime \prime}\right)$ measured at FPA. Since all the curves in the figure indicate approximately steady pyrolysis, the mass loss rates $(\dot{m})$ in the whole test periods were used.

$$
\begin{aligned}
& \dot{m}_{1}=\frac{\Delta m_{1}}{\Delta t}=\frac{m_{t=1100}-m_{t=159}}{1100-159}=\frac{30.54-0.32}{1100-159}=0.032 \mathrm{~g} / \mathrm{s} \text { at } \dot{q}_{e}^{\prime \prime}=20 \mathrm{~kW} / \mathrm{m}^{2}, \\
& \dot{m}_{2}=\frac{m_{t=900}-m_{t=67}}{900-67}=\frac{70.23-0.30}{900-67}=0.084 \mathrm{~g} / \mathrm{s} \text { at } \dot{q}_{e}^{\prime \prime}=35 \mathrm{~kW} / \mathrm{m}^{2}, \\
& \dot{m}_{3}=\frac{m_{t=650}-m_{t=51}}{650-51}=\frac{75.19-0.35}{650-51}=0.125 \mathrm{~g} / \mathrm{s} \text { at } \dot{q}_{e}^{\prime \prime}=50 \mathrm{~kW} / \mathrm{m}^{2}, \\
& \dot{m}_{4}=\frac{m_{t=570}-m_{t=46}}{570-46}=\frac{75.89-0.30}{570-46}=0.144 \mathrm{~g} / \mathrm{s} \text { at } \dot{q}_{e}^{\prime \prime}=60 \mathrm{~kW} / \mathrm{m}^{2} .
\end{aligned}
$$

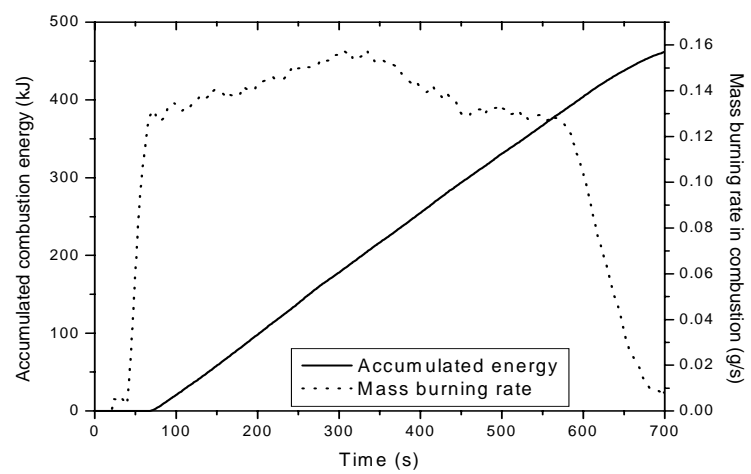

Fig. 5. Accumulated combustion energy and burning rate of \#1089. 


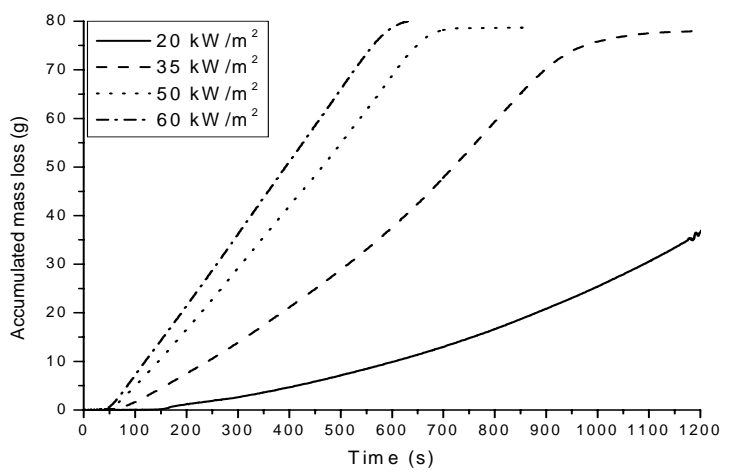

Fig. 6. Accumulated mass loss in pyrolysis of \#1089.

When $\dot{m}$ was converted to a mass loss rate per unit area by using the sample surface area of $0.00694 \mathrm{~m}^{2}, \quad \dot{m}_{1}^{\prime \prime}=4.61 \mathrm{~g} / \mathrm{m}^{2} . \mathrm{s}, \quad \dot{m}_{2}^{\prime \prime}=12.10 \mathrm{~g} / \mathrm{m}^{2} . \mathrm{s}, \quad \dot{m}_{3}^{\prime \prime}=18.01 \mathrm{~g} / \mathrm{m}^{2} . \mathrm{s}$, and $\dot{m}_{4}^{\prime \prime}=20.75$ $\mathrm{g} / \mathrm{m}^{2}$.s were obtained. Figure 7 shows the linear curve fit of $\dot{q}_{e}^{\prime \prime}$ vs. $\dot{m}^{\prime \prime}$, from which the slope of the curve and the "critical heat flux" can be obtained. The slope in the figure indicates that the critical heat flux is $7.51 \mathrm{~kW} / \mathrm{m}^{2}$ and the heat of gasification is $2.43 \mathrm{~kJ} / \mathrm{g}$.

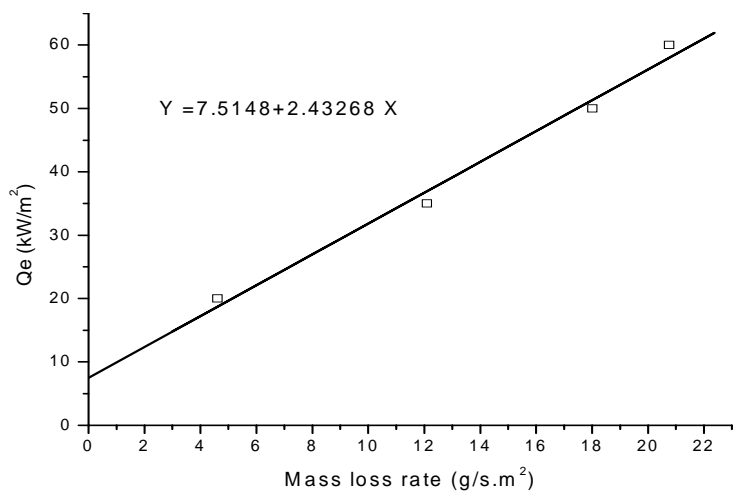

Fig. 7. Curve fitting of $\dot{m}^{\prime \prime}$ vs. $\dot{q}_{e}^{\prime \prime}$ in pyrolysis of \#1089.

Estimation of $\dot{Q}_{c h} v s . \dot{Q}_{b}$

The values of $\Gamma=\frac{5.90}{2.43}=2.43$ and $\mathrm{Y}_{\mathrm{sp}}=0.173$ were used to solve Eq. 3 in conjunction with $\dot{Q}_{b}=28,38$, and $59 \mathrm{~kW}$.

\section{Item \#1098 (Plywood)}

Figure 8 shows a comparison of mass pyrolysis rates between \#1089 and \#1098 at $\dot{q}_{e}^{\prime \prime}=$ $60 \mathrm{~kW} / \mathrm{m}^{2}$. It is clear that while the rate of pyrolysis of \#1089 was almost steady, that of \#1098 shows multiple peaks, indication of the strong effects of initial charring and rapid final burnout of the material. As mentioned earlier (see 3.3), instead of the average of the total pyrolysis mass loss, the average mass loss rates only at the first peak, which was estimated through the accumulated mass loss curve, were used in the computation. That gave $\dot{m}_{1}^{\prime \prime}, \dot{m}_{2}^{\prime \prime}, \dot{m}_{3}^{\prime \prime}$, and $\dot{m}_{4}^{\prime \prime}$ as $1.22,5.43,10.13$, and $13.16 \mathrm{~g} / \mathrm{m}^{2} . \mathrm{s}$, respectively. 


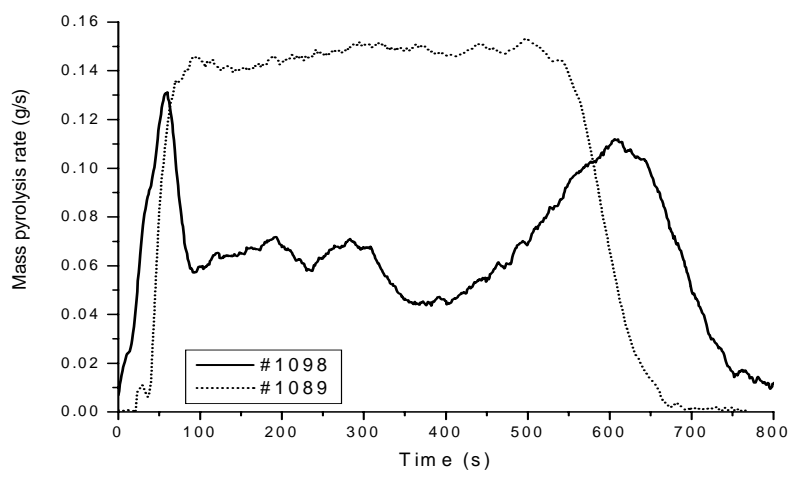

Fig. 8. Comparison of mass loss rates in pyrolysis of \#1098 and \#1089.

Figure 9 shows the linear curve fitting of $\dot{m}^{\prime \prime}$ vs. $\dot{q}_{e}^{\prime \prime}$, from which the "critical heat flux" can be obtained as $16.3 \mathrm{~kW} / \mathrm{m}^{2}$ and the heat of gasification is estimated as $3.33 \mathrm{~kJ} / \mathrm{g}$. All other properties associated with combustion were obtained based on the total period of combustion at FPA as shown in 4.1.1 and 4.1.2. The $\Delta H_{c}$ and $Y_{s p}$ came out as $11.34 \mathrm{~kJ} / \mathrm{g}$ and $6.54 \times 10^{-2}$, respectively. The $\dot{Q}_{c h}$ of $\# 1098$ was estimated by solving Eq. 3 with $\Gamma=\frac{11.34}{3.33}=3.41, Y_{s p}=6.54 \times 10^{-2}$, and $\dot{Q}_{b}=92 \mathrm{~kW}$.

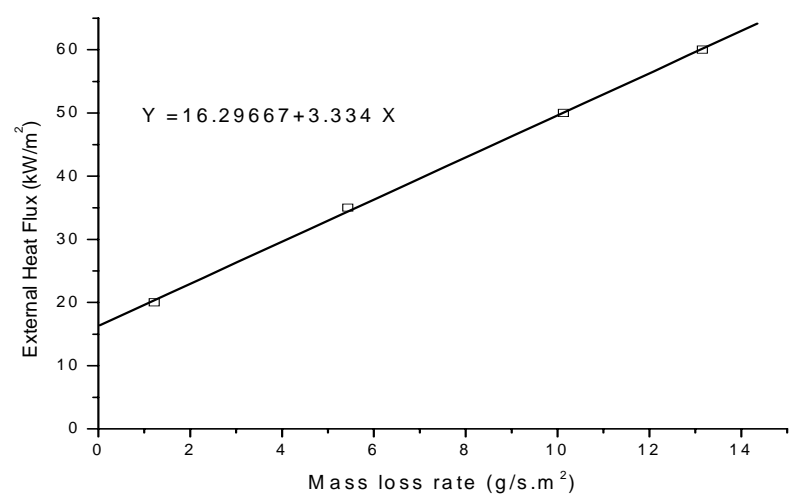

Fig. 9. Curve fitting of $\dot{m}^{\prime \prime}$ vs. $\dot{q}_{e}^{\prime \prime}$ in pyrolysis of \#1098.

\section{OVERALL COMPARISON OF ESTIMATION OF $\dot{Q}_{c h}$ VS. $\dot{Q}_{b}$}

The total estimated heat release rate at each parallel panel test is given in Table 1. The $\dot{Q}_{c h}$ of the materials $\# 1089,1090,1095$, and 1117 was computed in a similar way described for that of \#1089, while the $\dot{Q}_{c h}$ of the materials \#1096, 1097 and 1098 was obtained by a similar way as that of \# 1098. Overall the comparison between the measured and the estimated heat release rates was good. "SFP" at $\dot{Q}_{c h}$ of \#1098 referred to "sustained fire propagation." The numerical solution of Eq. 3 showed an unbounded behavior. The iterations simply keep increasing the value.

It was found that the total heat release rate at the PPT apparatus was approximately $350 \mathrm{~kW}$ when fire reached the top of the panels, regardless of the panel material. Thus, a 
predicted heat release rate greater than $350 \mathrm{~kW}$ is taken as indicating fire propagation at least to a height of $2.4 \mathrm{~m}$. Table 1 shows that the estimated chemical heat release rates match well, except one, with the observed flame propagation. The one exception was the case with \#1090 under $\dot{Q}_{b}=64 \mathrm{~kW}$. The estimated $\dot{Q}_{c h}$ was $481 \mathrm{~kW}$, but fire propagation was not observed. Given the otherwise good agreement, repeating the bench-scale and the parallel panel tests is planned.

\section{COMPARISON OF THE 25 FT CORNER TESTS WITH PPT RESULTS}

A comparison of the results of full-scale $25 \mathrm{ft}$ Corner Tests with that of parallel panel tests is given in Table 2. Here "FR Plywood" referrers to "Fire Retarded Plywood." In the parallel panel tests simulating the $25 \mathrm{ft}$ Corner Tests, the heat release rates from the sand burner were varied between $60 \mathrm{~kW}$ and $100 \mathrm{~kW}$, which were the standard exposure and the maximum available exposure, respectively, with the current PPT apparatus.

Table 2. Comparison of the $25 \mathrm{ft}$ corner test results with that of PPT.

\begin{tabular}{|c|c|c|c|c|}
\hline \multirow{2}{*}{$\begin{array}{l}\text { Material } \\
\text { Number }\end{array}$} & \multirow{2}{*}{ Material Description } & \multirow{2}{*}{$\begin{array}{l}\text { Thickness } \\
\text { (mm) }\end{array}$} & \multicolumn{2}{|c|}{ Fire Propagation } \\
\hline & & & $\begin{array}{c}25 \mathrm{ft} \text { Corner } \\
\text { Test }\end{array}$ & $\begin{array}{c}\text { PPT (Exposure in } \\
k W)\end{array}$ \\
\hline 1117 & $\mathrm{PVC}$ & 12.6 & Yes in $7.5 \mathrm{~min}$ & Yes in $13 \min (60)$ \\
\hline 1097 & FR Plywood & 19.5 & No in $15 \mathrm{~min}$ & No in $20 \min (103)$ \\
\hline 1096 & FR Plywood & 12.7 & No in $15 \mathrm{~min}$ & No in $20 \min (100)$ \\
\hline 1107 & FR Plywood & 6.4 & No in $15 \mathrm{~min}$ & Yes in $4-5 \min (80)$ \\
\hline 1047 & Fiberglass Reinforced Polymer & 2.0 & No in $15 \mathrm{~min}$ & No in $18 \min (60)$ \\
\hline
\end{tabular}

The results in Table 2 appear to indicate that the PPTs predict the outcome of the $25 \mathrm{ft}$ Corner Tests accurately except for the case with $6.4 \mathrm{~mm}$ thick FR plywood (\#1107). Although the plywood passed the $25 \mathrm{ft}$ Corner Test, the PPT showed the flame propagation beyond the maximum height, $2.4 \mathrm{~m}$, within 3-4 min when the exposures were higher than $80 \mathrm{~kW}$, indicating a would-be propagation in the $25 \mathrm{ft}$ corner test. However, in both tests, a portion of the material burned completely through its thickness. In the case of the $25 \mathrm{ft}$ Corner Test, the burning-through resulted in no further flame propagation. In the PPT, however, the propagating flame, separated from the initial source flame and as a result of the burn-through, reached the top of the panels, $2.4 \mathrm{~m}$. When the same material was exposed to the same fire source, $80 \mathrm{~kW}$, in a $4.9 \mathrm{~m}$ high PPT, the upper flame front, which was separated from the main flame near the base of the panels, propagated beyond $2.4 \mathrm{~m}$ high but stopped at $3.5 \mathrm{~m}$ high. Thus, if the panels were higher than the current $2.4 \mathrm{~m}$, the prediction would have indicated the same outcome as the $25 \mathrm{ft}$ Corner Test.

Among the test materials in Table 2, the PVC is the material of most interest for practical applications of interior/exterior plastic panels as well as of being a material showing the marginal behavior. Thus, whether or not the behavior of PVC at the PPT conforms to that 
in the $25 \mathrm{ft}$ Corner Test should be a strong indication of an acceptable simulation. In Table 2, the PVC took off at $7.5 \mathrm{~min}$ after ignition in the $25 \mathrm{ft}$ Corner Test and it did at $11 \mathrm{~min}$ in the PPT when the exposure was $80 \mathrm{~kW}$. Thus, the comparison seems to suggest that the PPT predicted accurately the result of the Corner Test. However, considering that the test fire in the corner test was a growing one so that it took a considerable incipient time before it was able to develop a meaningful heat flux while the fire source in the PPT was a steady one that took no time to be the specified exposure, one can conclude that the exposure at the current PPT apparatus was not adequate to simulate the actual $25 \mathrm{ft}$ corner test.

Measurements of PVC performance in the current $2.4 \mathrm{~m}$ high PPT suggests that the PVC is marginally flammable. Being marginal makes the PVC a good material for demarking the go/no-go condition of flammability tests. The $12 \mathrm{~mm}$ thick PVC propagated after an extended time of 11 minutes with an $80 \mathrm{~kW}$ exposure in the current PPT apparatus. Past performance of PVC of various thicknesses indicated that thicker specimens required greater heat flux to propagate. Also the time for propagation increased significantly with thickness. The impression was that the PVC had to almost burn through its entire thickness near the base before it propagated. This is indicative of thermally thin behavior-i.e., propagation depends on heat propagating to the rear of the sample at which point less heat is required by the sample for vaporization, because any necessary preheating has already taken place. In the PPT when the sample thickness was increased to $19 \mathrm{~mm}$, no propagation occurred within the first 20 minutes. That led to an expectation that $19 \mathrm{~mm}$ thick samples would not propagate in the $25 \mathrm{ft}$ Corner Test and the $12 \mathrm{~mm}$ thick material would either non-propagate or marginally propagate.

The result for the $12 \mathrm{~mm}$ thick PVC in the $25 \mathrm{ft}$ Corner Test (see Table 2), however, was quite different than the anticipated result. It vigorously propagated at 7.5 minutes---that is just a 2.5 min after the flames barely reached the top of the pallet stack. Examination of the fuel after the test showed that there was minimal in depth heating. Only a little fuel near the surface burned. The propagation behavior was clearly that for a surface spread over a thermally thick solid---very different from that in the current PPT apparatus.

Three reasons can be given for this difference in behavior: (1) The current PPT apparatus does not provide a sufficiently high heat flux to produce a thermally thick fire spread for the PVC, (2) The current PPT apparatus provides too small a flow time for the pyrolysis vapors to yield their true heat of combustion, (3) The PVC pyrolysis vapors dramatically enhance the flame heat flux from the pallet stack in the $25 \mathrm{ft}$ Corner Test. This enhancement occurs due to the significant amount of soot from the PVC vapors that are injected into the $4 \mathrm{MW}$ flames from the relatively smoke free wooded pallet flames.

Recognizing that these characteristics of material flammability cannot be scaled, the most important parameter that needs to be replicated in the PPT apparatus should be the heat flux imposed to the target material from the fire source being used in the $25 \mathrm{ft}$ Corner Test. The fire source is a $1.5 \mathrm{~m}$ high stack of wood pallets, the HRR of which was measured about $4 \mathrm{MW}$ [8]. The peak heat flux immediately above the top of the wood stack was $100 \mathrm{~kW} / \mathrm{m}^{2}$ [8]. When the heat fluxes to inert walls imposed by the sand burner at the current apparatus were measured, the maximum heat flux was $66 \mathrm{~kW} / \mathrm{m}^{2}$ with the $102 \mathrm{~kW}$ exposure. Thus, the PPT apparatus needs to be modified in such a way that the apparatus can provide heat fluxes to panels that are about $100 \mathrm{~kW} / \mathrm{m}^{2}$. The geometric dimensions of the panels also must be increased accordingly in order to: (1) contain the enlarged sand-burner flames within the panels, and (2) clearly demonstrate flame propagations caused by the burning specimen, if any. 


\section{CONCLUSION}

To reach a goal of predicting outcome of $25 \mathrm{ft}$ Corner Tests (full-scale fire tests) by analyzing material flammability data (bench-scale tests), parallel-panel tests (intermediate-scale tests) were explored as a stepping stone. As the first step of the journey, a simple model was developed to predict the fire propagation at parallel panel tests by utilizing a minimum amount of material flammability data obtained through bench-scale tests. The total heat release rates from the burning parallel panels predicted by the model were compared with those measured through the real tests conducted with varying fire exposures at the bottom of the parallel panels of various materials. The results of the comparison were very favorable indicating a good first step in the direction of finding an alternative to the $25 \mathrm{ft}$ Corner Tests.

The comparison between the results of the parallel panel tests and the corresponding fullscale $25 \mathrm{ft}$ Corner Tests indicates a feasibility to correlate the results between the two sets of the tests. A new parallel panel test apparatus with greater heat exposures, currently under construction, is expected to provide a stronger correlation between the results of the Corner Tests and that of the parallel panel tests.

\section{REFERENCES}

[1] Approval Standard: Class I Insulated Wall or Wall \& Roof/Ceiling Panels; Plastic Interior Finish Materials; Plastic Exterior Building Panels Wall/Ceiling Coating Systems; Interior or Exterior Finish Systems; Class Number 4880, FM Approvals, 1151 Boston-Providence Turnpike, Norwood, Massachusetts, USA, August, 1994.

[2] FM Approvals, Cleanroom Materials, Flammability Test Protocol, Class Number 4910, FM Approvals, 1151 Boston-Providence Turnpike, Norwood, Massachusetts, USA, September 1997.

[3] Alpert, R.L., "Evaluation of the Hazard of Fire Resistance Materials Using Measurements from Laboratory and Parallel Panel Tests," Proceedings, Fire Safety Science of the $7^{\text {th }}$ Int'l Symposium, Evans, D.D. (ed.), International Association for Fire Safety Science, pp. 41-57, 2003.

[4] ASTM E 2058, "Standard Test Method for Measurement of Synthetic Polymer Material Flammability Using a Fire Propagation Apparatus (FPA)," Annual Book of ASTM Standards, Vol. 4.07, American Society for Testing and Materials, West Conshohocken, PA, USA, 2001.

[5] de Ris, J.L, and Orloff, L., "Flame Heat Transfer between Parallel Panels Inferred from Flame Volumes," Accepted for IAFSS $8^{\text {th }}$ International Symposium for Fire Safety Science.

[6] Schug, K.P., Manheimer-Timnat, Y., Yaccarino, P., and Glassman, I., "Sooting Behavior of Gaseous Hydrocarbon Diffusion Flames and the Influence of Additives," Combustion Science and Technology, 22, 1980, pp. 235-250.

[7] Tewarson, A., "Generation of Heat and Chemical Compounds in Fires," The SFPE Handbook of Fire Protection Engineering ( $3^{\text {rd }}$ ed), DiNenno P. J. (ed.), National Fire Protection Association, Quincy, MA, USA, 2002, pp. 3-131 to 3-137.

[8] Alpert, R.L., and Davis, R.J., "Evaluation of Exterior Insulation and Finish System Fire Hazard for Commercial Applications," J. of Fire Protection Engineering, 12, 2002. 